\title{
Hideo Mitani
}

- Professor Emérito da Tohoku University, Japan.

- Graduado em Odontologia pela Osaka Dental University.

- Mestre em Ciências, Ortodontia, pela University of Illinois.

- Doutor pela Tokyo Medical and Dental University.

- Ex-professor Assistente de Ortodontia da University of Illinois.

- Ex-chefe do Departamento de Ortodontia da Universidade de Illinois.

- Ex-chefe do Departamento de Ortodontia da Tohoku University.

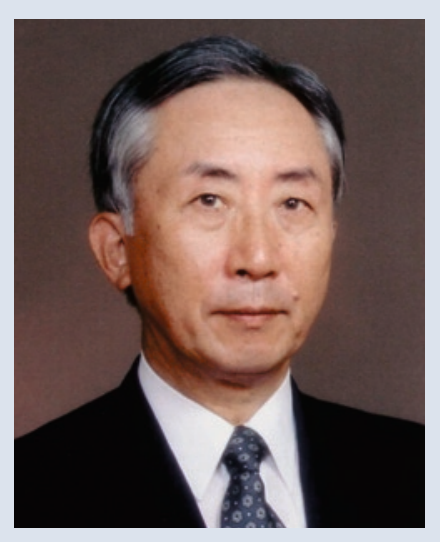

- Ex-diretor da Faculdade de Odontologia da Tohoku University.

- Ex-vice-reitor da Tohoku University.

- Ex-professor Visitante das universidades Kyongpook National (Coreia) e da University of Illinois.

- Ex-vice-presidente da Japanese Orthodontic Society.

- Ex-presidente da Tohoku Orthodontic Society.

- Ex-membro da Executiva da World Federation of Orthodontics.

- Ex-presidente da Asian Pacific Orthodontic Society.

- Membro honorário da Japanese Orthodontic Society.

- Membro da Edward H. Angle Society of Orthodontics, Midwest Component.

Quando abordado pela Revista Dental Press de Ortodontia e Ortopedia Facial para conduzir a entrevista do Prof. Hideo Mitani passei a viver um momento de muita alegria, para não dizer de uma certa euforia. Conheço bem o Prof. Mitani, pessoalmente e pela sua importante contribuição para a literatura ortodôntica. Juntos participamos, anualmente, dos encontros da Angle Society, Midwest Component, e lá temos a chance de uma interação sempre positiva e construtiva.

Passado o primeiro momento de euforia, busquei nomes importantes para contribuírem com perguntas e agradeço aos Prof. Ademir Brunetto e, em especial, ao Prof. Peter Ngan, pela magnífica contribuição.

Um fato interessante é que, isoladamente, cada um de nós fez uma série de perguntas e, ao colocá-las juntas, observamos uma convergência para os mesmos tipos de questionamentos. Assim, a entrevista foi trabalhada a três cabeças e seis mãos.

O tratamento das Classes III é controverso e nesta conversa com o Professor Mitani, uma das maiores autoridades mundiais no assunto, essas áreas de desacordo ficam bem evidenciadas.

Nosso entrevistado tem um currículo invejável e se tornaria impossível enumerar sua valiosa obra. Vale destacar, entretanto, que o professor Mitani é Professor Emérito da Tohoku University no Japão. Formou-se em Odontologia pela Osaka University, é Mestre em Ortodontia pela University of Illinois e fez seu doutorado na Tokyo Medical and Dental University.

Obrigado a todos pela oportunidade e pelo trabalho, incluindo aqui, a equipe de entrevistadores e de editores da Dental Press.

Eustaquio Araújo 
É uma grande honra e um privilégio ter a oportunidade de compartilhar minha filosofia, pensamentos e conhecimento com os leitores da Revista Dental Press de Ortodontia e Ortopedia Facial.

Espero que minhas respostas aprofundem a discussão sobre este tema tão intrigante e que este conhecimento seja capaz de proporcionar um melhor entendimento na abordagem da má oclusão de Classe III.

Agradeço sinceramente aos professores Drs. Peter Ngan, Ademir Brunetto e Eustaquio Araújo, pela formulação de perguntas tão interessantes.

Em artigo recente publicado no Seminars in Orthodontics ${ }^{13}$, o senhor menciona que os efeitos ortopédicos das mentoneiras incluem:

1) redirecionamento do crescimento mandibular;

2) reposicionamento mais posterior da mandíbula;

3) retardo de crescimento mandibular nos côndilos; e

4) remodelação da morfologia mandibular na região do ângulo goníaco e da sínfise.

No seu entendimento, esses efeitos são de curta ou longa duração? Favor comentar levando em conta os estudos, clínicos e com animais, disponíveis na literatura.

Em relação ao redirecionamento do crescimento mandibular e do reposicionamento mais posterior da mandíbula, esses estão presentes somente durante o uso da mentoneira. Cessado o uso do aparelho, a mandíbula retorna ao direcionamento original de crescimento. Em relação ao retardo no crescimento mandibular ao nível dos côndilos, esse parece estar presente no período inicial de 2 a 3 anos de uso do aparelho. Ao que tudo indica, a mandíbula readquire seu potencial de crescimento após esse tempo. No que se refere à remodelação na morfologia mandibular, as alterações no ângulo goníaco e na sínfise passam a ser definitivas, ou pelo menos são encaradas como duradouras, levando um tempo enorme para serem retomadas.

Em relação à literatura, a maioria dos estudos clínicos concorda com os efeitos de redirecionamento do crescimento, do reposicionamento da mandíbula e da remodelação morfológica ${ }^{1,3,6,8,15,17,19,24}$.

Os estudos em animais dificilmente se aplicam aos humanos, devido às diferenças na morfologia da face e da mandíbula. As condições também são extremamente mais complexas nos humanos. Portanto, os efeitos das mentoneiras em humanos se diferenciam grandemente daqueles em animais.

Em relação ao retardo no crescimento no nível dos côndilos, diversos estudos em animais demonstram efeitos histológicos positivos, mas esses estudos são, na maioria, de curta duração $2,9,10,11,17,18,21$. Alguns de longa duração foram realizados em humanos. Esses, normalmente, demonstram que uma retrusão mandibular acontece nos estágios iniciais do uso da mentoneira ${ }^{15,19,23}$. Essas são as bases para o resultado no retardo do crescimento mandibular, apesar de não haver comparação histológica em humanos.

Sabemos de seu trabalho com mentoneira em um par de gêmeas idênticas. Seria possível comentar a recuperação de crescimento observada?

As gêmeas em questão podem ser vistas na figura 1. Inicialmente, antes do tratamento, demonstravam tamanho e forma mandibular praticamente idênticos (Fig. 3A). Comecei a terapia com mentoneira na irmã $\mathrm{B}$ e deixei a irmã $\mathrm{A}$ em observação, sem qualquer intervenção terapêutica. Dois anos mais tarde, elas demonstravam diferença significativa nos aspectos dentário e facial (Fig. 2).

Cuidadosamente, fiz seus traçados evidenciando as imagens dos côndilos. A gêmea que usou a mentoneira demonstrava um tamanho de mandíbula menor, com um ângulo goníaco mais agudo, em comparação à outra, sem tratamento (Fig. 3B). Ficou claro que o crescimento havia sido retardado pela mentoneira.

Após dois anos de uso da mentoneira, contudo, suspeitou-se que a cartilagem condilar gradualmente havia se adaptado à força da mentoneira, permitindo que a atividade de crescimento retornasse ao nível inicial. A direção de crescimento 

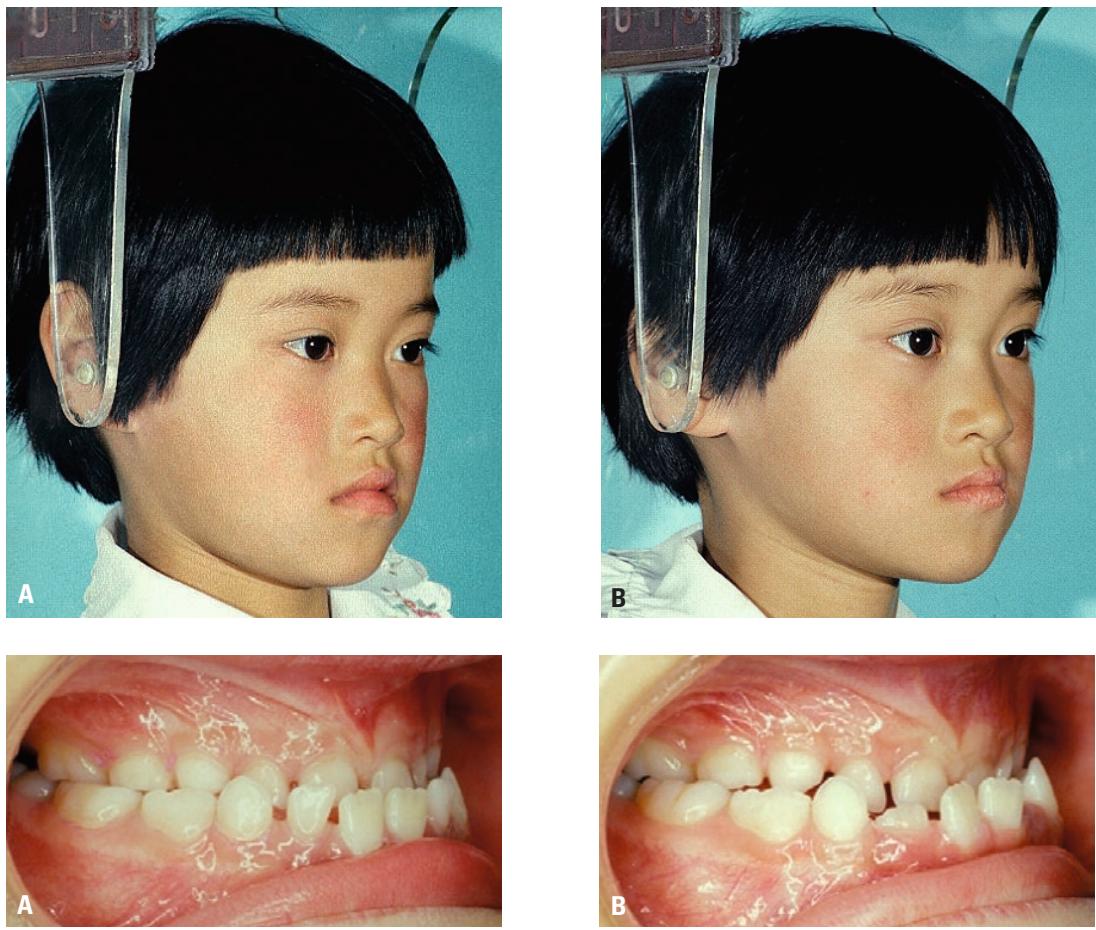

FIGURA 1 - Gêmeas idênticas com prognatismo mandibular e mordida cruzada anterior. A irmã A foi observada, sem uso de mentoneira, por 2 anos, enquanto a irmã B fez uso da mentoneira pelos mesmos dois anos (Fonte: MITANI $\left.{ }^{13}, 2007\right)$.
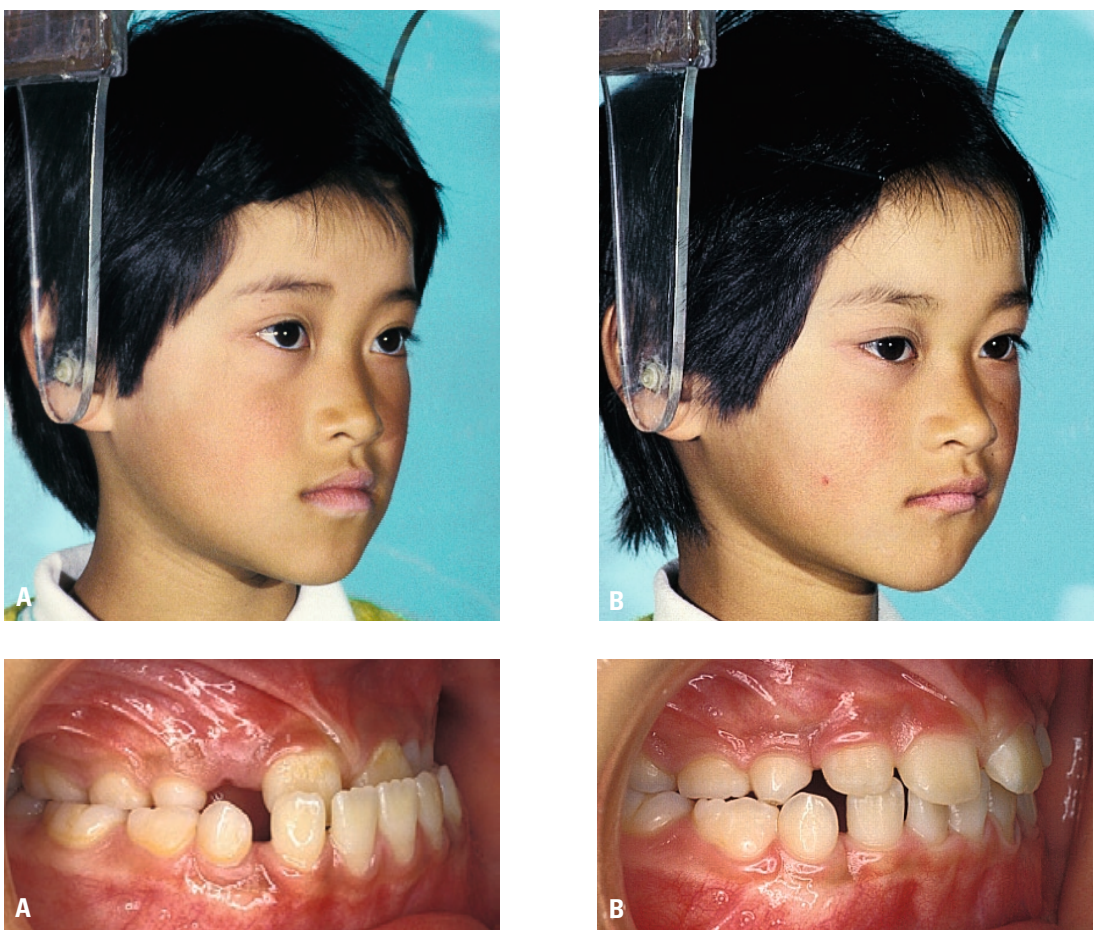

FIGURA 2 - Análise da face e da oclusão após dois anos. A mordida cruzada anterior foi corrigida na irmã B, por meio do uso da mentoneira. Observa-se a diferença no perfil das duas irmãs (Fonte: MITANI'13, 2007). 

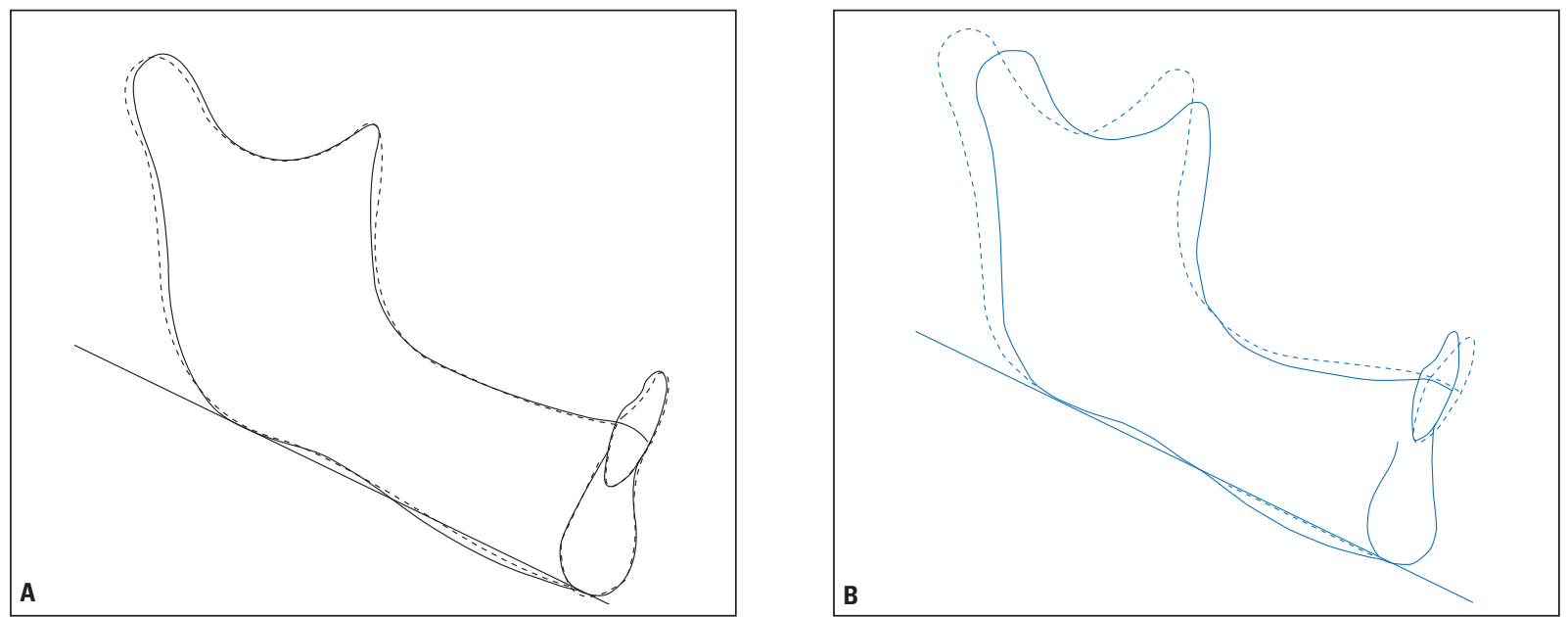

FIGURA 3 - A) Antes da utilização da mentoneira, o tamanho e a forma das mandíbulas das gêmeas eram praticamente idênticos. B) Após dois anos, as duas mandíbulas apresentaram clara diferença em tamanho e forma (linha pontilhada = irmã A, sem mentoneira; linha contínua = irmã B, com mentoneira) (Fonte: MITANI' ${ }^{13}$, 2007).

também retomou a direção inicial. Finalmente, cessado o crescimento, suas mandíbulas começavam a mostrar tamanho e forma semelhantes (Fig. 4, 5). As mudanças começaram a ser percebidas logo após a interrupção no uso da mentoneira. Através dessa evidência, comecei a acreditar que uma recuperação parcial do crescimento acontece na mandíbula quando o uso da mentoneira é interrompido antes do final do crescimento.

A interrupção das forças compressivas na região condilar, conforme já relatado, se efetivada antes de terminado o crescimento, estimularia e aceleraria o mesmo $\mathrm{o}^{4,5,20}$. Isso pode ser um indicativo de que a mandíbula tenta retomar seu tamanho original determinado morfogeneticamente. Assim sendo, recomenda-se enfaticamente o uso das mentoneiras até que o crescimento tenha se completado.

Nos países asiáticos há um número significativo de portadores de Classe III com deficiência maxilar e excesso mandibular. Qual sua abordagem para esses pacientes?

Meu protocolo padrão para o tratamento da Classe III em pacientes com idade mais jovem (precoce) é o uso de força ortopédica aplicada à mandíbula e/ou maxila, dependendo da origem esquelética do problema.

De forma sucinta, quando a maxila é deficiente e a mandíbula normal em tamanho e posição, uma protração maxilar será a primeira intervenção escolhida. Essa terapia é implementada, às vezes, conjuntamente a uma expansão da maxila e tem como objetivo um avanço maxilar e/ou estímulo de crescimento.

Nos casos de uma maxila normal, em tamanho e posição, e excesso mandibular, o uso da mentoneira deve ser considerado. Essa terapia tem por objetivo retardar ou redirecionar, no sentido posterior e inferior, o crescimento de uma mandíbula anormal.

Nos casos de uma maxila deficiente e de um excesso mandibular, uma combinação de mentoneira e máscara facial passa a ser a escolha. Com isso, objetivamos obter os benefícios da mentoneira e da máscara facial, simultaneamente.

Mentoneiras, há muito tempo, fazem parte de minha terapia em casos de excesso mandibular. O motivo é que, pelo menos até o presente momento, não há outro mecanismo capaz de retardar o prognatismo mandibular quando um paciente e/ou seus pais desejam melhoras mais rápidas e 

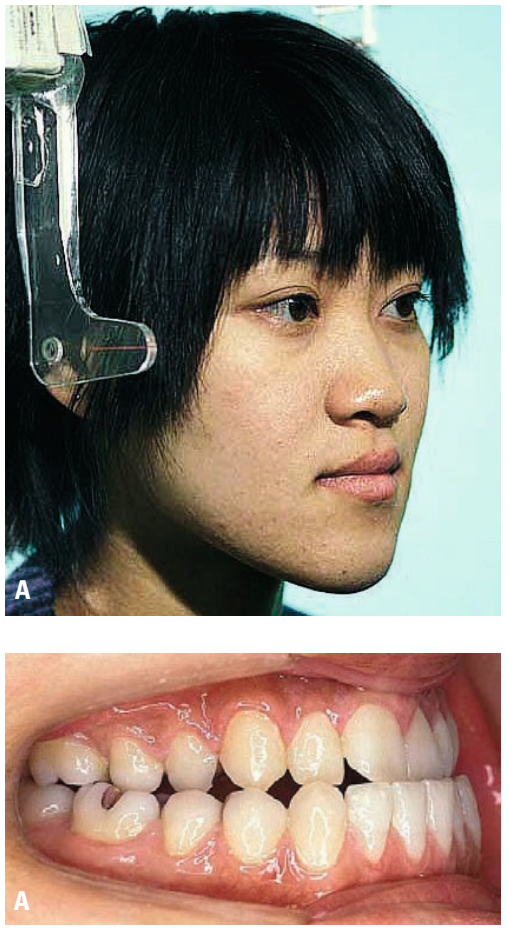

FIGURA 4 - Oclusão e face aos 20 anos de idade. Nenhum outro tratamento, exceto a mentoneira, foi utilizado na irmã B (Fonte: MITANI'13, 2007).
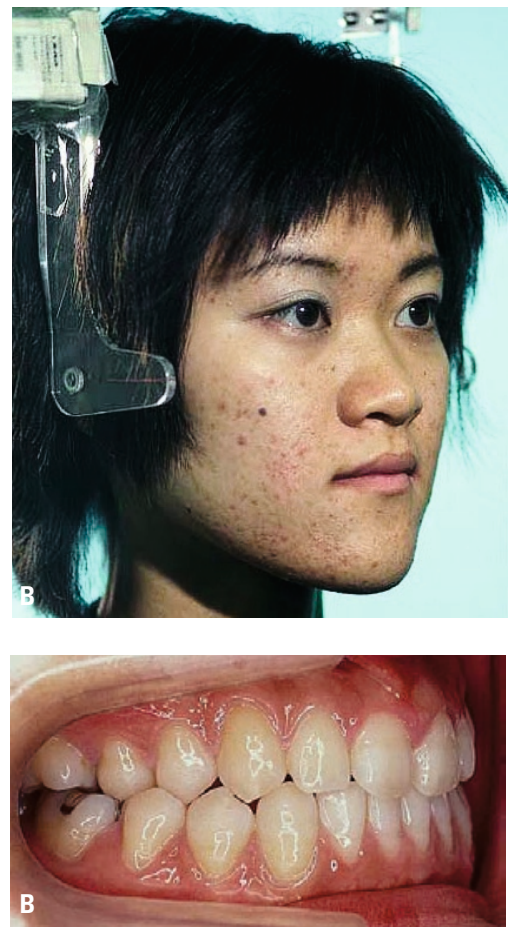

hum outro tratamento, exceto a mentoneira, fo

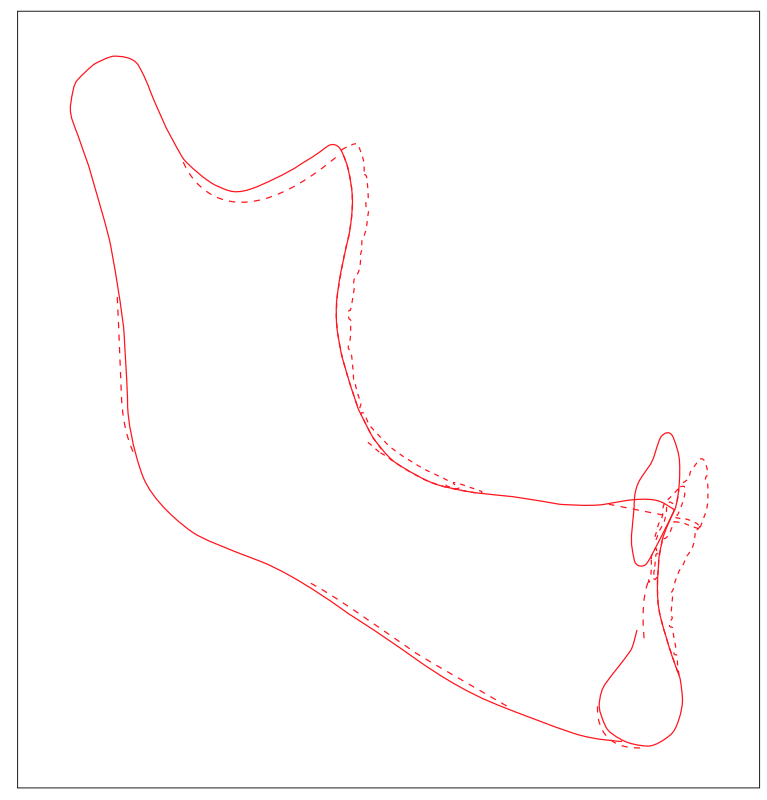

FIGURA 5 - Sobreposição das mandíbulas das irmãs A e B tendo como referência 0 plano mandibular e a sínfise, aos 20 anos de idade. 0 tamanho e a forma finais de ambas as mandíbulas voltaram a ser praticamente iguais, exceto pela posição dos incisivos inferiores (linha pontilhada = irmã $A$, sem mentoneira; linha contínua = irmã $B$, com mentoneira) (Fonte: MITANI ${ }^{13}$, 2007). sem recursos cirúrgicos, principalmente nos perfis. Quero deixar claro que não exijo 24 horas de uso do aparelho. O tempo solicitado é do final da tarde até a manhã do dia seguinte.

Também é necessário esclarecer que os efeitos das mentoneiras variam consideravelmente, de acordo com cada tipo facial. Por exemplo, uma face longa típica não deve receber indicação de mentoneira, pois seu uso contribuiria para acentuar o problema. Também numa face curta e com o ângulo goníaco mais agudo o resultado indicaria uma redução ainda maior do ângulo goníaco e uma ausência do desejado movimento mandibular inferior e posterior (sentido horário). Nesses casos, observaríamos uma piora do padrão facial. Assim, a seleção do padrão estrutural da face deve acontecer antes de se implementar a modalidade de tratamento.

A protração com máscara facial é bastante efetiva num primeiro momento e por um período relativamente curto. Mordidas cruzadas anteriores 
podem ser facilmente corrigidas. Como afirmei anteriormente, a terapia realizada em conjunto com uma expansão da sutura palatina facilita a protração e o crescimento maxilar no sentido anterior. Contudo, é preciso observar que o resultado dentário é bem maior que o ósseo. Também chamo a atenção para o fato de a maxila normalmente apresentar um deslocamento rotacional anti-horário o que pode determinar uma abertura de mordida.

\section{Na sua vasta experiência, há benefícios re- ais no tratamento da Classe III em paciente de idade mais jovem? Nesse caso, que tipo de pacientes se beneficiariam da conduta e quando deve ser iniciado o tratamento? Qual seria o protocolo? Quais parâmetros indicam um sucesso no tratamento? Quais tipos de caso devem, desde cedo, ser considerados casos cirúrgicos?}

Num paciente Classe III em crescimento, torna-se necessário, inicialmente, conhecer as expectativas do paciente e dos pais. É importante saber se há o desejo de uma correção somente do problema dentário (normalmente uma mordida cruzada anterior) ou se o objetivo é o de uma correção facial, com ou sem cirurgia. Às vezes, também, a expectativa é da abordagem de ambos os problemas. Esclarecidos os objetivos, passamos a examinar o padrão estrutural do paciente.

Em relação à época do tratamento, é necessária uma consideração de todas as variáveis presentes. Quando um paciente apresenta um distúrbio de origem funcional, como uma mordida cruzada ou topo-a-topo, acrescida ou não de uma mordida cruzada lateral, mau alinhamento e outros desvios, não recomendo adiar uma intervenção. Esses problemas devem ser abordados o mais cedo possível. No caso das má oclusões topo-a-topo, sua correção se torna imprescindível, para se evitar trauma e danos às raízes dos dentes anteriores. Uma mordida cruzada funcional também tem que ser abordada o mais cedo possível, evitando-se distúrbios na ATM. Mordidas cruzadas laterais também devem ser corrigidas bem cedo, para se prevenir desvios na mandíbula. Outra abordagem necessária é a do posicionamento mais inferior da língua, que deve ser enfocado nos estágios iniciais de desenvolvimento, já que dificulta a contenção das correções da Classe III.

Os efeitos das mentoneiras são mais significativos em idade precoce ${ }^{22}$. Na adolescência, há uma maior variação nas respostas ao uso das mentoneiras e, assim, observa-se resultados mais individua$\operatorname{lizados}^{14}$. Isso provavelmente se deve ao fato das diferenças individuais na atividade de crescimento (magnitude) durante esse período. Reluto em usar mentoneiras em pacientes em fase de crescimento puberal, com o objetivo de retardar o crescimento mandibular. Prefiro iniciar o uso das mentoneiras antes do paciente entrar no período de crescimento puberal.

Contudo, como afirmei anteriormente, clinicamente não é recomendável liberar a cartilagem condilar das forças de compressão enquanto houver um potencial de crescimento. Assim sendo, as mentoneiras devem ser mantidas até o fim do crescimento. Isso inibe uma eventual recuperação de crescimento. A quantidade de recuperação do crescimento que efetivamente poderá ocorrer dependerá, no entanto, da quantidade de crescimento remanescente e da quantidade do efetivo retardo obtido desde o início do uso da mentoneira. $\mathrm{O}$ padrão hereditário do paciente também deve ser considerado. Assim, a maneira com que a mentoneira é utilizada varia de indivíduo para indivíduo.

$\mathrm{Na}$ minha experiência, considero difícil completar um caso quando a morfologia da mandíbula apresenta as seguintes características: (1) protrusão mandibular com a sínfise formando um ângulo do mento agudo, (2) tamanho mandibular acentuado (Cd-Gn), (3) ângulo goníaco aberto e plano mandibular acentuado, (4) plano posterior do ramo mandibular com acentuada inclinação, (5) côndilo fino e longo, (6) ramo ascendente estreito, (7) corpo mandibular em formato mais triangular, (8) incisivos inferiores retroinclinados, (9) ângulo da base craniana mais agudo e com a sincondrose esfeno-occipital já fechada (Fig. 6). 
Nesses casos, recomendo adiar o tratamento, desde que o paciente possa conviver com o seu problema. Isso se dá pelo fato de que o uso das mentoneiras e/ou máscaras faciais dificilmente se torna eficiente, permanecendo um alto risco de recidiva do prognatismo. Esses pacientes deveriam ser tratados com cirurgia ortognática. Ao mesmo tempo, é necessário se investigar a genética do paciente. Se há uma evidência de uma linha familiar de Classe III, prefiro aguardar para uma intervenção pós-crescimento.

É preciso ficar claro, no entanto, que alguns estudos comprovam a correlação do prognatismo com uma grande baixa-estima e dificuldade de integração no convívio social, o que pode levar a sérios distúrbios emocionais. Nesses casos, quando o paciente se pune por sua aparência e deseja muito uma correção, recomendo o início do tratamento, desde que a família e o paciente tenham conhecimento das dificuldades e de uma possível recidiva e desde que tenham consentido, por escrito, com o início do procedimento. Acredito que tal conduta seja relevante para o futuro emocional do paciente.

De acordo com a literatura e também em sua experiência, a partir de que idade é recomendável uma intervenção ortognática num paciente Classe III?

Meus estudos indicam que o padrão morfológico de uma face com prognatismo se estabelece bem cedo e que, assim que estabelecido, o crescimento continua de maneira similar ao de uma face normal ${ }^{12}$. Contudo, é preciso se observar que os índices de variação para cada um dos fenômenos (quantidade, velocidade, época e magnitude do crescimento) são maiores numa face prognática, quando comparada a uma face normal. Assim, algumas faces com prognatismo demonstram mudanças relativamente moderadas com o tempo, mas outras podem apresentar um prognatismo acentuado com o crescimento. Isso quer dizer que os índices médios de crescimento não devem ser considerados como padrão num indivíduo com prognatismo.

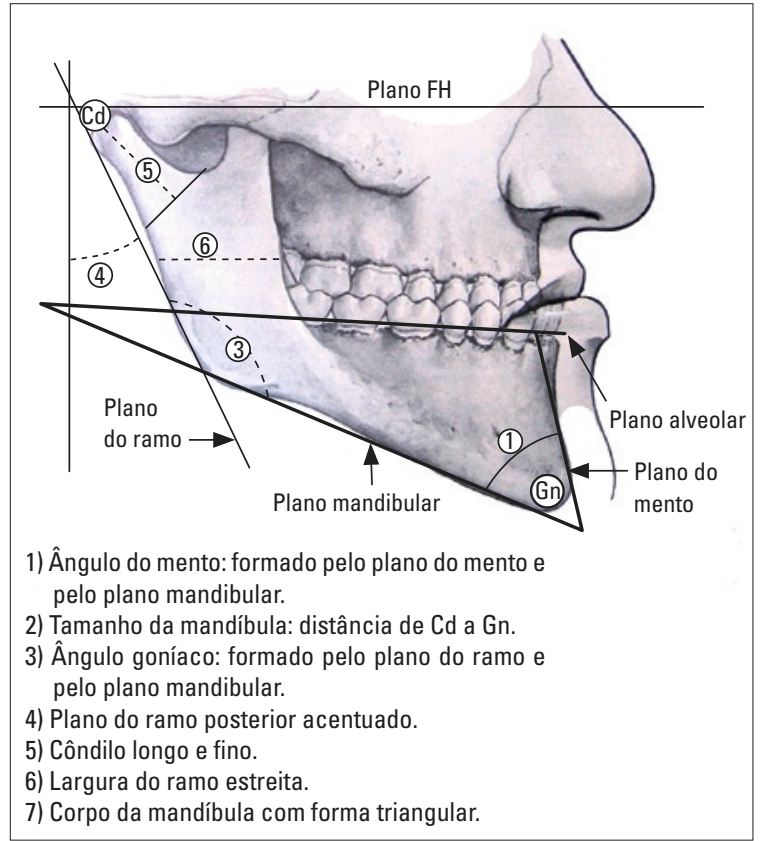

FIGURA 6 - Aspectos a serem observados para uma possível indicação cirúrgica.

Acrescenta-se a isso o fato de que a formação e o desenvolvimento de um prognatismo estão também ligados a outras variáveis, como a genética e o padrão esquelético, muscular e hormonal. Por exemplo, um aumento no prognatismo depende não só da quantidade de crescimento da mandíbula, mas também da configuração da base craniana e de seu potencial de crescimento. Quando o ângulo da base craniana for mais agudo e o crescimento da parte posterior da base craniana (sincondrose esfeno-occipital) se encerrar mais cedo que o normal, o prognatismo piora durante o crescimento.

Em relação ao final do crescimento mandibular, alguns casos podem se estender até bem mais tarde, assim como numa mandíbula normal. Deve-se observar também o tamanho e a posição da língua. Línguas muito grandes e em posição mais inferior, normalmente, se tornam um fator agravante para o tratamento. Assim, pelo menos até agora, é difícil de se fazer uma previsão ou de se estimar o crescimento de forma precisa e torna-se difícil estabelecer um plano de tratamento definitivo. A cirurgia ortognática deve ser realizada após a 
conclusão do crescimento. Desconheço, até o momento, bons resultados de procedimentos cirúrgicos em pacientes de Classe III realizados antes do final de crescimento. No futuro, tais intervenções podem até acontecer, mas precisamos de estudos mais completos sobre o crescimento e a adaptação pós-operatória de mandíbulas em crescimento.

\section{Há uma grande controvérsia na literatura so- bre os feitos das mentoneiras na articulação temporomandibular. Qual sua posição sobre esse assunto?}

Há necessidade de se entender a natureza não fisiológica da ação de uma mentoneira na ATM e na sua função. Assim sendo, é razoável suspeitar que algumas complicações na articulação possam acontecer em casos em que as ATM's não toleram tal força. Cada côndilo tem morfologia própria e quantidades diferentes de cartilagem de crescimento. Assim, a formação óssea nos diversos tipos de côndilo apresenta uma atividade de crescimento distinta (magnitude de crescimento). A magnitude de crescimento e os valores de resistência em nível condilar respondem cada um a seu modo, diante de forças compressivas. Clinicamente, contudo, não é possível se determinar esses valores. Em suma, uma força "ótima" ou "ideal" é difícil de ser determinada. Sendo assim, em alguns casos, pode acontecer uma sobrecarga.

Nossos estudos indicam que algum estalido ou dor possam ser observados, nos primeiros seis meses de tratamento, em cerca de 35\% dos pacientes ${ }^{7}$. Quando a mentoneira é usada mais de 16 horas por dia, esses sintomas podem aparecer a qualquer momento, até mesmo em percentual maior.

\section{REFERÊNCIAS}

1. ARMStRONG, C. J. A clinical evaluation of the chin cup. Aust. Dent. J., Sydney, v. 16, p. 338-346, 1961.

2. ASANO, T. Effects of mandibular retractive force to growth of rat mandible. J. Jap. Orthod. Soc., Tokyo, v. 44, p. 19-20, 1985.
Quanto maior o período de uso diário, maiores e mais complexos os sintomas. Dessa forma, como já enfatizado anteriormente, não recomendo o uso do aparelho durante o dia todo, preferindo o uso noturno, iniciado ao fim da tarde. Podemos destacar a magnitude da força e o tempo de uso diário como variáveis importantes nas desordens temporomandibulares.

Esses sintomas desaparecem por si só em alguns pacientes, mas nem sempre em outros. A incidência dos sintomas diminui gradualmente após cessado o uso do aparelho e, de acordo com a literatura, esses sintomas não se tornam crônicos. Normalmente, há uma ausência de sintomas, em níveis variados, quando interrompido o uso das mentoneiras ${ }^{16}$.

$\mathrm{Na}$ presença de sintomas, indico a diminuição da força e uma redução no tempo de uso diário. Se a situação perdurar, após 1 ou 2 meses, interrompo o procedimento. Antes da instalação de uma mentoneira, é necessário uma anamnese e exame da ATM. Durante a terapia, conversas, inspeção e ausculta devem se tornar uma rotina.

\section{CONSIDERAÇÕES FINAIS}

Algumas controvérsias ainda existem em relação ao uso das mentoneiras. Não recomendo ou rejeito a terapia. Espero, no entanto, que os ortodontistas possam explorar o potencial das mesmas quando da seleção de uma conduta clínica mais adequada. Acredito que um aparelho por si só não seja capaz de determinar a qualidade de um tratamento. $\mathrm{O}$ conhecimento e o bom senso dos profissionais, sim, são mais importantes. Agradeço pela oportunidade e pela leitura desta entrevista.
3. CLEALL, J. F. Dentofacial Orthopedics. Am. J. Orthod., St. Louis, v. 66, p. 237-250, 1974.

4. COPRAY, J. C. V. M.; JANSEN, H. W. B.; DUTERLOO, H. S. Effects of compressive forces on proliferation and matrix synthesis in mandibular condylar cartilage of the rat in vitro. Arch. Oral Biol., Philadelphia, v. 30, p. 299-304, 1985.

5. ENLOW, D. H. The facial growth process: handbook of facial growth. Philadelphia: W. B. Saunders, 1975.

6. GRABER, L. W. Chin cup therapy for mandibular prognathism. Am. J. Orthod., St. Louis, v. 72, p. 23-41, 1977. 
7. INAI, Y.; MITANI, H.; FUKAZAWA, H.; MUKAIYAMA, T. Changes of temporomandibular function with chincap-orthodontic treatment for anterior reversed occlusion. Tohoku Univ. Dent. J., Sendai, v. 11, p. 67-74, 1992.

8. IRIE, M.; NAKAMURA, S. Cephalometric changes in treatment of anterior cross-bite cases with the chin cap. J. Jap. Orthod. Soc., Tokyo, v. 31, p. 75-86, 1972.

9. JANZEN, E. K.; BLUHER, J. A. The cephalometric anatomic and histologic changes in the Macaca mulatta after application of a continuous-acting retraction force on the mandible. Am. J. Orthod., St. Louis, v. 51, no. 11, p. 823-855, Nov. 1965.

10. JOHO, J. P. The effects of extraoral low-pull traction to the mandibular dentition of Macaca mulatta. Am. J. Orthod. St. Louis, v. 64, p. 555-577, 1973.

11. MATSUI, Y. Effect of chin cap on the growing mandible. J. Jap. Orthod. Soc., Tokyo, v. 24, p. 165-181, 1965.

12. MITANI, H. Prepubertal growth of mandibular prognathism. Am. J. Orthod. St. Louis, v. 80, p. 546-553, 1981.

13. MITANI, H. Recovery growth of the mandible after chin cup therapy - fact or fiction. Semin. Orthod., Philadelphia, v. 13 no. 3, p. 186-199, Sept. 2007.

14. MITANI, H.; FUKAZAWA, H. Effects of chincap force on the timing and amount of mandibular growth associated with anterior reversed occlusion (Class III malocclusion) during puberty. Am. J. Orthod. Dentofacial Orthop., St. Louis, v. 90, p. $454-463,1986$

15. MITANI, H.; SAKAMOTO, T. Chin cap force to a growing mandible: long-term clinical reports. Angle Orthod., Appleton, v. 54, p. 93-122, 1984

16. MORIKAWA, A.; MITANI, H.; INAI, Y.; KUWABARA, S. FUKAZAWA, H. Prevalence of temporomandibular dysfunction after chincap-orthodontic treatment. Tohoku Univ. Dent. J. Sendai, v. 12, p. 61-68, 1993.

17. NANDA, R. Biomechanical and clinical considerations of a modified protraction headgear. Am. J. Orthod., St. Louis, v. 78, p. $125-139,1980$

18. NOGUCHI, K. Effects of extrinsic forces on the mandibular condyle of the young rat: observation using $3 \mathrm{H}$-thymidine autoradiography. J. Jap. Stomat. Soc., Tokyo, v. 37, p. 222-241, 1970

19. NUKATSUKA, S. The longitudinal study of orthopedic effects caused by chin cap treatment. Tohoku Univ. Dent. J., Sendai, v. 1, p. 1-17, 1982

20. PETROVIC, A. Mechanism and regulation of mandibular condylar growth. Acta Morph. Neerl. Scand., Lisse, v. 10, p. 25-34, 1972.

21. PETROVIC, A. G.; STUTZMAN, J J. OUDET C. L Control processes in the postnatal growth of the condylar cartilage of the mandible. Effects of orthopedic therapy on condylar growth. In: McNAMARA JR., J. A. Determinants of mandibular form and growth. Ann Arbor: University of Michigan, 1975. p. 106-113.

22. SAKAMOTO, T.; IWASE, I.; UKA, A.; NAKAMURA, S. A roentgenocephalometric study of skeletal changes during and after chin cup treatment. Am. J. Orthod., St. Louis, v. 85, p. 341-350, 1984

23. SUGAWARA, J.; ASANO, T.; ENDO, N.; MITANI, H. Long-term effects of chincap therapy on skeletal profile in mandibular prognathism. Am. J. Orthod. Dentofacial Orthop., St. Louis, v. 98, p. $127-133,1990$.

24. SUZUKI, N. A cephalometric observation on the effect of the chin cap. J. Jap. Orthod. Soc., Tokyo, v. 31, p. 64-74, 1972.

\section{Ademir Roberto Brunetto \\ Pós-graduado em Ortodontia pela Universidade da Califórnia, Los Angeles (UCLA). \\ - Professor de graduação e pós-graduação da disciplina de Ortodontia - UFPR. \\ - Diplomado pelo Board Brasileiro de Ortodontia. \\ - Diretor do Board Brasileiro de Ortodontia. \\ - Consultor científico da revista clínica de Ortodontia da Dental Press.}

\section{Eustaquio Araújo}

- Cirurgião-dentista pela UFMG.

- Mestre em Ortodontia pela University of Pittsburgh, PA.

- Professor e diretor assistente da área de Ortodontia do Center for Advanced Dental Education, Saint Louis University, St. Louis, MO.

- Diplomado pelo Board Brasileiro de Ortodontia.

- Diretor do Board Brasileiro de Ortodontia.

- Membro da Edward H. Angle Society of Orthodontics, Midwest Component.

- Membro do International College of Dentists e do American College of Dentists.

\section{Peter Ngan}

- Cirurgião-dentista pela Harvard University.

- Mestre em Ortodontia pela University of Pennsylvania, PA.

- Professor e diretor do Departamento de Ortodontia da West Virginia University.

- Responsável pela área de Odontologia Infantil, West Virginia University.

- Diplomado pelo American Board of Orthodontics.

- Diplomado pelo American Board of Pediatric Dentistry. - Membro do American College of Dentists.
Endereço para correspondência

Hideo Mitani, DDS. MS. PhD

E-mail: mitani@mail.tains.tohoku.ac.jp 